\title{
Digital Analysis Of Sales And Industry Partition: An Examination Of U.S. Public Companies
}

Dominique Geyer, Audencia Nantes School of Management, France

\begin{abstract}
Previous studies have shown that companies' managers tend to round-up reported earnings (Carslaw, 1988; Thomas, 1989; Niskanen \& Keloharju, 2000) and sales revenue (Jordan et al., 2009). The frequency of zero as second digit in earnings and sales is much higher than expected frequency. The current study confirms this finding for sales in a sample of U.S. public companies but further shows that this rounding behavior is focused on only few industries. Another finding is that for the financial industry, round-up behaviour is significantly more important for large firms.
\end{abstract}

Keywords: Nbenford’s Law; Digital Analysis; Earnings And Sales Management; Industry Partition

\section{INTRODUCTION}

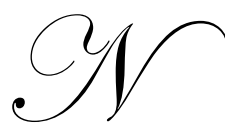

umerous studies show that managers round up earnings or sales to achieve cognitive reference points. For example, when a firm has a positive earning of $\$ 29.97$ millions, managers will round-up to $\$ 30$ millions in order to influence perceptions of financial statement users. Psychological studies (e.g. Rosh, 1975; Gabor and Granger, 1966) demonstrate that humans use numbers in multiples of ten as yardsticks in their perception and judgement of other numbers.

Such rounding-up behavior is typically called cosmetic earnings (or sales) management (hereafter CEM or CSM). Most previous empirical studies in accounting are focused on CEM. Thus the purpose of this paper is to examine CSM of a sample of U.S. public firms. The aim is to examine whether industry partition and the firm's size possess significant explanatory power for CSM.

The results indicate that CSM of U.S. public firms is focused on few industries. For the financial sector, we show that the larger the firm is, the more likely the firm is to engage in CSM.

The paper is organized into four sections. Section 1 describes Benford's law which is the origin of digital analysis. Section 2 presents the literature review. While the third section presents the methodology and the results. The concluding section summarizes the results and presents the limitations of the study.

\section{BENFORD'S LAW AND DIGITAL ANALYSIS}

Digital analysis is a method of analyzing the patterns of digits in set of numbers. Consider the following data set: the sales of a sample of U.S. public firms. Each number can be described by the digits utilized. For example, the number $\$ 23$ millions has two digits: 2 is the first digit and 3 is the second digit. When looking up the data set, it is one believed that the frequency of digit 1 as the first digit is 1/9. However, the mathematician and astronomer Simon Newcomb demonstrated that this is not the case.

In an article published in 1881, Newcomb noted that the first pages of his logarithm table book were more worn than the others. He deduced that the searchers preferred to work with numbers starting with 1 rather than by 2 ; numbers starting with 2 being preferred to those starting with 3 , and so on. Intuitively this observation will appear 
strange insofar as one could think that there is an equiprobability of appearance of the various digits.

From this surprising discovery, Newcom proposed the following formula indicating the probability that a number extract from a set of numbers has $C$ as first digit $(C$ is an integer between 1 and 9$)$ : $\log 10[1+(1 / C)]$. This discovery went unnoticed and some 57 years later a physicist of General Electric, Franck Benford, made the same observation as Newcomb (always with the logarithms tables). However, Benford spent many years collecting data in order to validate this law. His article in 1938 registers twenty lists of numbers with 20,229 observations from several sources, such as geographic, scientific and demographic data to test this law.

In a data set obeying Benford's law, approximately $30.1 \%$ of numbers have 1 as the first digit whereas this percentage falls to $4.6 \%$ for the numbers having 9 as first digit. This law can be generalized with the second, third, etc digits. One can formalize this law for numbers having two digits c1 c2; (for example, the number 23 has two digits, the first digit $\mathrm{c} 1$ is 2 and the second digit $\mathrm{c} 2$ is 3 ); the generalization to $\mathrm{N}$ digits is immediate:

- probability of the event : the first digit of a number of a data set is $\mathrm{c} 1$ :

$\mathrm{P}(\mathrm{C} 1=\mathrm{c} 1)=\log 10(1+(1 / \mathrm{c} 1))$ with $\mathrm{c} 1 \in\{1 ; 2 ; 3 ; 4 ; 5 ; 6 ; 7 ; 8 ; 9\}$

- probability of the event: the second digit of a number of a data set is $\mathrm{c} 2$ :

$$
\mathrm{P}\left(\mathrm{C}_{2}=\mathrm{c}_{2}\right)=\sum_{\mathrm{c}_{1}=1}^{9} \log _{10}\left(1+\left(1 / \mathrm{c}_{1} \mathrm{c}_{2}\right)\right) \text { with } \mathrm{c}_{2} \in\{0 ; 1 ; 2 ; 3 ; 4 ; 5 ; 6 ; 7 ; 8 ; 9\}
$$

Thus the probability that a number of a data set obeying Benford's law for 23 is $\log 10(1+(1 / 23))=0.0184$. For 3 digits, the formula becomes simply:

$\mathrm{P}(\mathrm{C} 1 \mathrm{C} 2 \mathrm{C} 3=\mathrm{c} 1 \mathrm{c} 2 \mathrm{c} 3)=\log 10(1+(1 / \mathrm{c} 1 \mathrm{c} 2 \mathrm{c} 3))$. The following table shows the expected frequencies in the first three positions.

Table 1: Benford's law: expected digital frequencies

\begin{tabular}{|c|c|c|c|}
\hline & \multicolumn{2}{|c|}{ Position in Number } \\
\hline Digit & First & Second & Third \\
\hline 0 & & 0.11968 & 0.10178 \\
1 & 0.30103 & 0.11389 & 0.10138 \\
3 & 0.17609 & 0.10882 & 0.10097 \\
4 & 0.12494 & 0.10432 & 0.10057 \\
5 & 0.09691 & 0.10031 & 0.09979 \\
6 & 0.07928 & 0.09668 & 0.09940 \\
7 & 0.06695 & 0.09337 & 0.09902 \\
9 & 0.05799 & 0.09035 & 0.09864 \\
\end{tabular}

Note: the number 482 has 3 digits: 4 is the first digit, 8 the second and 2 the third. This table shows that under Benford's law the expected proportion of numbers with a first digit 4 is $9.69 \%$ (8.75\% with 8 as second digit and $10.09 \%$ with 2 as third digit).

\section{LITERATURE REVIEW}

The empirical studies concerning Benford's law in accounting have often examined the same issue: insofar as an accounting data set follows Benford's law, tests which show significant variations between the observed frequencies and the theoretical frequencies can highlight fraud. The first application can be attibuted to Carslaw (1988). He examined the second digit of profit in a sample of New Zealand firms. He noted that for the second digit there is an excess of 0 and a lack of 9. The reason is simple: managers will tend to round up the firm's profit in order to embellish the situation. Consider a profit of 49.98 million euros. Rounding this number to 50 million provides a psychological influence whose importance will be greater whereas the second number is only marginally more important than the first. 
This first study was followed by Thomas (1989) who studied samples of U.S. companies. He examined earnings before extraordinary items and discontinued operations at the quarterly and annual level. His study is more nuanced than Carlslaw (1988) because he distinguished profits from losses. He also noted an excess of 0 for the second digit of profits. In loss cases, one rounds down (less 0 and more 9) whereas in the profit level, one will rather round up. At the per share level, Thomas noted that multiples of 5 and 10 cents are observed considerably more often than others numbers. The same CEM have been observed among Finnish (Niskanen and Keloharju, 2000) and English firms (Van Caneghem, 2002).

The study by Kinnumen and Koskela (2003) introduced an international comparative dimension. Using a sample of approximately 87,000 earnings observations from almost 22,000 firms in 18 countries, the authors found that upward rounding is much more significant on the bottom line than on the top of an income statement. Another interesting finding is that the rounding behavior is influenced by some institutional factors like spending on auditing or the importance of management bonus schemes.

Van Caneghem (2004) examined the impact of audit quality on earnings rounding up behavior of UK firms. The author used two proxies to capture differences in audit quality on earnings management. For the first proxy (i.e. BigFive versus non-BigFive auditors), the findings show no significant difference beetween BigFive and nonBigFive clients. For the second proxy (i.e. based on auditors' industry expertise), findings are weakly consistent with specialist BigFive auditors constraining earnings management.

Skousen, Guan and Wetzel (2004) replicate the earlier studies for Japenese firms. Their sample consisted of 1,871 Japenese companies and 37,900 annual earnings observation from 1974 to 1997. Similar to previous studies, the authors find that the first digit of earnings is often emphasized by management. They note that rounding behavior is not limited to the first digit. The second, third and even fourth digits are sometimes used as the reference points of the rounding earnings behavior.

Guan, He and Yang (2006) examine 182,278 positive quarterly earnings observations and 103,470 negative quarterly observations for all publicly listed U.S. companies from 1993 to 2003. The results show that each of the four fiscal quarters is concerned by rounding behavior. But this behavior is significantly less severe in the fouth fiscal quarter (which is the only quarter audited) than any of the previous quarters.

Jordan, Clark and Hames (2009) demonstrate that for a sample of large publicly-traded U.S. companies rounding up behavior appear to be securing with respect to reported sales revenue. Using a sample of 1,002 U.S. publicly-traded companies (2006 financial statement data), the authors show evidence of a strong bias toward sales revenue numbers having zero as second digit.

Following this brief literature review, two points are important:

- $\quad$ Earning variables (i.e. earnings before extraordinary items, net income, earnings per share) are the most examined accounting variables in empirical studies concerning digital analysis. Two exceptions are the study of Jordan et al. (2009) which is focused on sales and Nigrini (1996) which used Benford's law in a U.S. tax compliance context.

- $\quad$ Few studies examined rounding-up behavior related to company characteristics. No prior study investigated for sales the relation between rounding up behavior and industry partition.

Hence, the aim of this short paper is to examine rounding up behavior for sales in U.S. public companies and to determine if the industry's branch of firms is related to these behaviors. Another aim is to examine whether firm' size is related to CSM.

\section{METHODOLOGY AND RESULTS}

The data used in this study are obtained from the Thompson One Banker database. The analysis includes data for sales and total assets for U.S. public active companies. Data concern the 2008 year period. In this database, the numbers are in millions of dollars. Numbers less than 10 millions dollars are excluded from the sample because 
the tests concern the first and the second digit. For the industry partition, the Global Industry Classification (GIC) Standard which was developed by MSCI and Standard \& Poor's is used.

Table 2: Digital Frequencies in the Second Position of Sales

\begin{tabular}{|c|c|c|c|c|c|}
\hline Digit & $\begin{array}{c}\text { No. of times } \\
\text { digit occurs } \\
\text { in 2nd position }\end{array}$ & $\begin{array}{c}\text { Observed } \\
\text { frequency } \\
(\boldsymbol{\%})\end{array}$ & $\begin{array}{c}\text { Expected } \\
\text { frequency } \\
(\boldsymbol{\%})\end{array}$ & Z value & P- level \\
\hline 0 & 658 & 13.314 & 11.968 & 2.916 & 0.004 \\
\hline 1 & 577 & 11.675 & 11.389 & 0.634 & 0.526 \\
\hline 2 & 503 & 10.178 & 10.882 & -1.589 & 0.112 \\
\hline 3 & 507 & 10.259 & 10.433 & -0.400 & 0.154 \\
\hline 4 & 473 & 9.571 & 10.031 & -1.076 & 0.714 \\
\hline 5 & 482 & 9.753 & 9.668 & 0.203 & 0.525 \\
\hline 6 & 470 & 9.510 & 9.337 & 0.419 & 0.572 \\
\hline 7 & 465 & 9.409 & 9.035 & 0.917 & 0.823 \\
\hline 8 & 402 & 8.134 & 8.757 & -1.549 & 0.991 \\
\hline 9 & 405 & 8.195 & 8.500 & -0.769 & 0.796 \\
\hline Sum & $\mathbf{4 , 9 4 2}$ & & & &
\end{tabular}

Note: The expected frequency is the proportion predicted by Benford's law.

For the analysis of sales, the sample concern 4,942 public U.S. companies. The results reported in Table 2 are consistent with previous studies. But this study isn't limited to the largest 1,002 U.S. public companies such as is the case with Jordan et al. (2009). The proportion of digit zero in the second place is higher than expected (significant at the $1 \%$ level). Contrary to previous studies, there is no significant lack of high digits $(7,8$ or 9$)$ at either the five or one percent level. The comparison of the observed distribution of Table 2 with the observed distribution of the sample of Jordan et al. (2009) shows no significant difference at the 10 percent level (Chi-square $=9.479, \mathrm{df}=9$, p-value $=0.394$ ). In other words, the CSM observed in 2006 in a sample of U.S. public companies continues in 2008.

These first findings concerning the rounding up behavior of U.S. public firms are deceptive because this behavior seems to be homogeneous in the sample. But this is a statistical illusion. Table 3 below shows a partition based on GIC industry membership. This Table considers only the case of zero as second digit. For brevity, the study does not present the tables for the nine other digits (from 1 to 9) because the observed proportions conform highly to the Benford distribution. Only three cases are significantly different from their expectations at the five percent level. The results are surprising because Table 3 shows that the rounding up behavior is focused on three industries: industrials, health care and financials at the ten percent level. The financial industry appears to have the largest unexpected deviations (see Table 5) and the Telecommunications Services industry exhibits the smallest deviations.

These inter-industry differences concerning CSM for zero as second digit are not due to chance because Table 4 shows for the same sample of U.S. public firms the results for total of assets. This variable is taken as a control variable because there is no reason to round up the total of assets. Table 4 demonstrates that there is no evidence of rounding behavior for the ten second digits (from 0 to 9). Reported deviations are not statistically significant from expected deviations at the ten percent level.

Until now the variable total of assets used as a control variable to demonstrate that CSM was not due to chance. However, this variable is useful to assess the firm's size. The aim is to test whether the firm's size is associated with the likelihood that sales will be manipulated. For each industry, small firms (firms which are under the median of the totals of assets) are distinguished from large firms (firms which are over the median). There is only one industry which exhibits significant differences: the financial industry. The subsample of large financial firms exhibits the largest deviations (see Table 6). For the subsample of small financial firms, CSM disappears (no excess of zeros, no lack of nines). Table 6 shows, consistent with previous studies, that one observes more zeros and fewer nines as second digit than what could be expected according to Benford's law. In addition, according to the 
Chi-square statistic, the null hypothesis of identical distributions for observed and expected frequencies of Benford's law is rejected at the 1 percent level. For the subsample of small financial firms, the null hypothesis is not rejected $($ Chi-square $=11.562, \mathrm{df}=9$, level of significance $=0.2392)$.

Table 3: Digital Frequencies for zero in the Second Position for sales

\begin{tabular}{|l|l|c|c|c|c|c|c|}
\hline $\begin{array}{l}\text { GIC } \\
\text { Code }\end{array}$ & Industry & $\begin{array}{c}\text { No. of times } \\
\text { zero occurs } \\
\text { in second position }\end{array}$ & $\begin{array}{c}\text { Number } \\
\text { Of firms }\end{array}$ & $\begin{array}{c}\text { Observed } \\
\text { frequency } \\
(\boldsymbol{\%})\end{array}$ & $\begin{array}{c}\text { Expected } \\
\text { frequency } \\
(\boldsymbol{\%})\end{array}$ & $\mathbf{Z}$ value & P- level \\
\hline 10 & Energy & 44 & 314 & 14.013 & 11.968 & 1.116 & 0.264 \\
\hline 15 & Materials & 32 & 240 & 13.333 & 11.968 & 0.652 & 0.515 \\
\hline 20 & Industrials & 97 & 669 & 14.499 & 11.968 & 2.017 & 0.044 \\
\hline 25 & Consumer Discretionary & 75 & 676 & 11.095 & 11.968 & -0.700 & 0.484 \\
\hline 30 & Consumer Staples & 35 & 218 & 16.055 & 11.968 & -1.479 & 0.139 \\
\hline 35 & Health Care & 58 & 505 & 11.485 & 11.968 & 1.859 & 0.063 \\
\hline 40 & Financials & 170 & 1175 & 14.468 & 11.968 & 2.640 & 0.008 \\
\hline 45 & Information Technology & 108 & 843 & 12.811 & 11.968 & 0.754 & 0.451 \\
\hline 50 & Telecommunication Services & 15 & 116 & 12.931 & 11.968 & 0.320 & 0.749 \\
\hline 55 & Utilities & 24 & 186 & 12.903 & 11.968 & 0.393 & 0.694 \\
\hline
\end{tabular}

Table 4: Digital Frequencies of zero in the Second Position of total of assets

\begin{tabular}{|l|l|c|c|c|c|c|c|}
\hline $\begin{array}{c}\text { GIC } \\
\text { Code }\end{array}$ & Industry & $\begin{array}{c}\text { No. of times } \\
\text { zero occurs } \\
\text { in 2nd position }\end{array}$ & $\begin{array}{c}\text { Number } \\
\text { of } \\
\text { firms }\end{array}$ & $\begin{array}{c}\text { Observed } \\
\text { frequency } \\
(\boldsymbol{\%})\end{array}$ & $\begin{array}{c}\text { Expected } \\
\text { frequency } \\
(\boldsymbol{\%})\end{array}$ & $\mathbf{Z}$ value & P- level \\
\hline 10 & Energy & 41 & 314 & 13.057 & 11.968 & 0.595 & 0.552 \\
\hline 15 & Materials & 35 & 240 & 14.583 & 11.968 & 1.248 & 0.212 \\
\hline 20 & Industrials & 91 & 669 & 13.602 & 11.968 & 1.302 & 0.193 \\
\hline 25 & Consumer Discretionary & 80 & 676 & 11.834 & 11.968 & -0.107 & 0.915 \\
\hline 30 & Consumer Staples & 33 & 218 & 15.138 & 11.968 & 1.442 & 0.149 \\
\hline 35 & Health Care & 65 & 505 & 12.871 & 11.968 & 0.625 & 0.532 \\
\hline 40 & Financials & 147 & 1175 & 12.511 & 11.968 & 0.573 & 0.567 \\
\hline 45 & Information Technology & 101 & 843 & 11.981 & 11.968 & 0.012 & 0.991 \\
\hline 50 & Telecommunication Services & 19 & 116 & 16.379 & 11.968 & 1.464 & 0.143 \\
\hline 55 & Utilities & 24 & 186 & 12.903 & 11.968 & 0.393 & 0.694 \\
\hline
\end{tabular}

Table 5: Digital Frequencies in the Second Position of Sales (Financial Firms)

\begin{tabular}{|c|c|c|c|c|c|}
\hline \\
\hline Digit & No. Of times & Observed & Expected & $\mathbf{Z}$ value & P-level \\
\hline 0 & 170 & 14,468 & 11,968 & 2,640 & 0,008 \\
\hline 1 & 129 & 10,979 & 11,389 & $-0,443$ & 0,658 \\
\hline 2 & 124 & 10,553 & 10,882 & $-0,362$ & 0,717 \\
\hline 3 & 132 & 11,234 & 10,433 & 0,898 & 0,369 \\
\hline 4 & 116 & 9,872 & 10,031 & $-0,181$ & 0,856 \\
\hline 5 & 100 & 8,511 & 9,668 & $-1,342$ & 0,179 \\
\hline 6 & 102 & 8,681 & 9,337 & $-0,773$ & 0,439 \\
\hline 7 & 105 & 8,936 & 9,035 & $-0,118$ & 0,906 \\
\hline 8 & 92 & 7,830 & 8,757 & $-1,124$ & 0,261 \\
\hline 9 & 105 & 8,936 & 8,500 & 0,536 & 0,592 \\
\hline Sum & 1175 & \multirow{3}{*}{\multicolumn{4}{|c|}{ Level of significance }} \\
\hline Chi-square & Degrees of freedom & & & & \\
\hline 10.778 & 9 & 0.2912 & & & \\
\hline
\end{tabular}


Table 6: Digital Frequencies in the Second Position of Sales

(Financial Firms with a total of assets larger than $\$ 1,190.83$ millions)

\begin{tabular}{|c|c|c|c|c|c|}
\hline Digit & $\begin{array}{c}\text { No. of times } \\
\text { digit occurs } \\
\text { in 2nd position }\end{array}$ & $\begin{array}{c}\text { Observed } \\
\text { frequency } \\
(\%) \\
\end{array}$ & $\begin{array}{c}\text { Expected } \\
\text { frequency } \\
(\%) \\
\end{array}$ & $Z$ value & P- level \\
\hline 0 & 95 & 16.184 & 11.968 & 3.147 & 0.002 \\
\hline 1 & 71 & 12.095 & 11.389 & 0.539 & 0.590 \\
\hline 2 & 62 & 10.562 & 10.882 & -0.249 & 0.803 \\
\hline 3 & 67 & 11.414 & 10.433 & 0.777 & 0.437 \\
\hline 4 & 57 & 9.710 & 10.031 & -0.259 & 0.796 \\
\hline 5 & 44 & 7.496 & 9.668 & -1.781 & 0.075 \\
\hline 6 & 50 & 8.518 & 9.337 & -0.682 & 0.495 \\
\hline 7 & 63 & 10.733 & 9.035 & 1.435 & 0.151 \\
\hline 8 & 42 & 7.155 & 8.757 & -1.373 & 0.170 \\
\hline 9 & 36 & 6.133 & 8.500 & -2.056 & 0.040 \\
\hline Sum & 587 & & & & \\
\hline quare & es of freedom & Lev & & & \\
\hline
\end{tabular}

\section{CONCLUSION}

Following Jordan et al. (2009), this study shows unusual patterns in reported sales. In a sample of 4,942 U.S. public firms, the paper demonstrates that managers round-up reported sales. The frequency of zero as second digit in sales is much higher than the expected frequency of Benford's law. But CSM is focused on three industries: industrials, health care and financials. These three industries represent $47.5 \%$ of the sample. This phenomenon is not due to chance because in the same sample, rounding-up behavior disappears for the control variable total of assets.

It is only for the financial industry that the firm's size (assessed by the variable total of assets) has an influence on CSM. The larger the firm is, the more likely the firm is to engage in CSM.

Because this study has an essentially exploratory nature, there are some limitations which need to be highlighted. The study collects data for only one year (2008) and one country. It is therefore necessary to validate the results with a more longitudinal analysis which includes a longer time horizon as well as other countries. Moreover the variable, total of assets, was chosen to assess the firm's size; it is possible that other variables have stronger explanatory power. Such suggestions could guide future research which examines the application of Benford's law.

\section{AUTHOR INFORMATION}

Dominique Geyer is Associate Professor at Nantes Audencia School of Management (France). He holds a Ph.D. from the University of Lille (France). His primary teaching areas are Financial Accounting and Management Accounting Information Systems. He has published articles in numerous journals, including Revue Francaise de Comptabilite, Revue Francaise de Gestion, Systeme d'Information et Management, European Management Journal, Journal of Computer Information Systems and Information and Management. E-mail: dgeyer@audencia.com.

\section{REFERENCES}

1. Benford, F., "The Law of Anomalous Numbers", Proceedings of American Philosophical Society, Vol.78, No. 4, pp. 551-572, 1938.

2. Carlslaw, C., "Anomalies in Income Numbers: Evidence of Goal Oriented Behavior", The Accounting Review, Vol. 63, No. 2, pp. 321-327, 1988.

3. Hill, T.P., "Base Invariance Implies Benford's Law", Proceedings of the American Mathematical Society, Vol. 123, pp. 887-895, 1995.

4. Hill, T.P., "The First Digit Phenomenon”, American Scientist, Vol. 86, pp. 358-363, 1998. 
5. Newcomb, S., "Note on the Frequency of Use of the Different Digits in Natural Numbers", The American Journal of Mathematics, 4, pp. 39-40, 1881.

6. Jordan, C.E., Clark, S.J. and Hames C., "Manipulating Sales Revenue To Achieve Cognitive Reference Points: An Examination Of Large U.S. Public Companies", The Journal of Applied Business Research, Vol. 25, No. 2, pp. 95-103, 2009.

7. Kinnunen J. et Koskela M., "Who is Miss World in Cosmetic Earnings Management ? A Cross-National Comparison of Small Upward Rounding of Net Income Numbers among Eigtheen Countries", Journal of International Accounting Research, Vol. 2, pp. 39-68, 2003.

8. Nigrini, M.J., "A Taxpayer Compliance Application of Benford's Law", Journal of the American Taxation Association, Vol. 18, No. 1: pp. 72-91, 1996.

9. Niskanen J. and Keloharju M., "Earnings Cosmetics in a Tax Driven Accounting Environment: Evidence from Finnish Public Firms", European Accounting Review, Vol.9, No. 3, pp. 443-452, 2000.

10. Thomas, J.K., "Unusual Patterns in Reported Earnings", The Accounting Review, Vol. 64, No. 4, pp. 773787, 1989.

11. Rosh, E., “Cognitive Reference Points”, Cognitive Psychology, pp. 532-547, 1975.

12. Skousen, J.C., Guan, L. and Wetzel T.S., "Anomalies and Unusual Patterns in Reported Earnings: Japanese Managers Round Earnings", Journal of International Financial Management, Vol. 15, No. 3, p. 212-234, 2004.

13. Van Caneghem T., "Earnings Management Induced by Cognitive Reference Points", British Accounting Review, Vol. 34, No. 2, pp. 167-178, 2002.

14. Van Caneghem T., "The Impact of Audit Quality on Earnings Rounding-up Behaviour: Some UK Evidence”, European Accounting Review, Vol. 13, No. 4, pp. 771-786, 2004. 


\section{NOTES}

